\title{
NEUROPHYSIOLOGICAL CORRELATES OF HYPNOTIC ANALGESIA
}

\author{
Audrey Vanhaudenhuyse ${ }^{1}$, Mélanie Boly ${ }^{1}$, Steven Laureys ${ }^{1}$ and \\ Marie-Elisabeth Faymonville ${ }^{2}$
}

${ }^{1}$ Coma Science Group, Cyclotron Research Centre and Neurology Department, University of Liege, Belgium, ${ }^{2}$ Department of Anaesthesia and Intensive Care Medicine, Pain Centre, University Hospital of Liege, Belgium

\begin{abstract}
This short review describes recent advances in understanding hypnotic modulation of pain. Our current understanding of pain perception is followed by a critical review of the hypnotic analgesia studies using EEG, evoked potential and functional imaging methodologies. Copyright (C) 2008 British Society of Experimental \& Clinical Hypnosis. Published by John Wiley \& Sons, Ltd.
\end{abstract}

Key words: pain, hypnosis, fMRI, PET-scan, EEG

After 200 years of inquiry and with varying popularity, the interest in hypnosis has more recently been on the upswing. The phenomena that comprise the domain of 'hypnosis' have attracted the curiosity of researchers and clinicians who have witnessed the changes in hypnotized subjects' behaviour and subjective experience. Evidence for the increasing interest in hypnosis in medical health care is demonstrated in the literature, where hypnosis can have an effective and cost-saving role (Holroyd 1996; Montgomery, DuHamel and Redd, 2000; Stewart 2005). However, there still remains controversy over how hypnosis should be defined. Some researchers (Hilgard 1965; Gruzelier 2000; Kallio and Revonsuo 2003) state that hypnotic phenomena cannot be explained without positing a special psychological state - an altered or dissociated state of consciousness, while others (Barber, 1969; Spanos, 1986; Kirsch, 1991) regard all phenomena seen in association with hypnosis as being explainable by using ordinary psychological concepts such as expectations or role playing.

The notion of consciousness is at the core of an ongoing debate on the nature of hypnosis. Consciousness is a multifaceted concept that can be conceived as having two major components: awareness of environment and of self (i.e. the content of consciousness) and wakefulness (i.e. the level of vigilance or arousal) (Laureys, 2005). The brain is functionally in a constant state of flux and alteration. There are now attempts to systematically explore and conceptualize the so-called altered states of consciousness within the context of neuroscience (Jamieson, 2007). At present, given the absence of a thorough understanding of the neural correlates of consciousness, results from neuroimaging studies should however be used with appropriate caution.

Contemporary scientific theories of hypnosis emphasize the changes in phenomenal experience where subjects interact in a larger sociocultural context that facilitates modifications in basic cognitive mechanisms underlying perception, memory and thought. 
Although still viewed with scepticism, hypnosis has gained respectability in medicine, in large part due to its demonstrated effects on analgesia (Montgomery, David, Winkel, Silverstein and Bobbjerg, 2002; Patterson and Jensen, 2003). Hypnosis can profoundly alter sensory awareness and cognitive processing and has been used for years to alleviate pain perception in many different clinical circumstances (Faymonville, Mambourg, Joris, Vrijens, Fissette, Albert and Lamy, 1997; Lang, Benotsch, Fick, Lutgendorf, Berbaum, Berbaum, Logan and Spiegel, 2000).

There has been a huge explosion in our understanding of the basic mechanisms of pain, yet despite advances in physiology, pharmacology and psychology, surveys repeatedly reveal that unrelieved pain remains a widespread problem. While we have long considered neurological pathways to be hard wired, it is becoming increasingly clear that the brain and the spinal cord are able to learn or facilitate activity in commonly utilized pathways. Functional neuroimaging studies revealed distinct anatomical pathways that are involved in the sensory and affective pain dimension. Pain is mediated via activation of a network of cortical and subcortical regions (Tölle, Kaufmann, Siessmeier, Lautenbacher, Berthele, Munz, Zieglgänsberger, Willoch, Schwaiger, Conrad and Bartenstein, 1999; Peyron, Laurent, Garcia and Larrea, 2000; Derbyshire, Jones, Creed, Starz, Meltzer, Townsend, Peterson and Firestone, 2002) but the interpretation of these findings is complicated by processes associated to the stimulus that are incidental to the actual sensory and emotional experience of pain. Such processes include motor inhibition, anticipation (Ploghaus, Tracey, Gati, Clare, Menon, Matthews and Rawlins, 1999; Hsieh, Stone-Elander and Ingvar, 1999), expectation (Carlsson, Petrovic, Skare, Petersson and Ingvar, 2000; Sawamoto, Honda, Okada, Hanakawa, Kanda, Fukuyama, Konishi and Shibasaki, 2000), attention (Bantick, Wise, Ploghaux, Clare, Smith and Tracey, 2002: Brooks, Nurmikko, Bimson, Singh and Roberts, 2002), distraction (Hoffman, Richards, Coda, Bills, Blough, Richards and Sharar, 2004) as well as the placebo effect (Petrovic, Kalso, Peterson and Ingvar, 2002; Ploghaus, Becerra, Borras and Borsook, 2003; Kupers, Faymonville and Laureys, 2005). Specific modulation of brain activity via manipulation of affective and sensory dimensions of pain experience (Derbyshire, Vogt and Jones, 1998; Coghill, Sang, Maisog and Iadarola, 1999) supported the existence of a neural functional pain mechanism. Derbyshire, Whalley, Stenger and Oakley in 2004 provided the first direct experimental evidence in humans linking specific neural activity with the immediate generation of a pain experience. They identified brain areas directly involved in the generation of pain using hypnotic suggestion to create an experience of pain in the absence of any noxious stimulus. In contrast to the imagined pain, fMRI revealed significant changes during this hypnotically induced pain experience within the thalamus, anterior cingulate, insula, prefrontal and parietal cortices and these findings differentiate the activation patterns during pain from nociceptive sources. Since 1980, a new era of methodological advances for non-invasive imaging of the human brain has forged a link between psychology and neurosciences. Budding efforts to study psychological processing using single photon emission computed tomography (SPECT), positron emission tomography (PET) and more recently functional magnetic resonance imaging (fMRI) have focused on measuring regional changes in cerebral haemodynamic activity (Laureys, Boly and Tononi, 2008). The advent of these brain imaging techniques have permitted to disentangle the brain mechanisms involved in pain and its cognitive modulation. The 'gate control' theory, proposed by Melzack and Wall in 1965, according to which activation in large myelinated fibers is capable of inhibiting nociceptive information, was the first model striking against the belief that pain processing is a hard-wired process, mediated exclusively by pain dedicated pathways. Later on, Melzack and Casey 
(1968) described pain as a complex multidimensional experience comprising sensorydiscriminative, motivational-affective and cognitive-evaluative components. This theory added a rostral (cerebral) extension to the gate control theory where cognition, e.g. distraction (Hoffmann et al., 2004), attention (Valet, Sprenger, Boecker, Willoch, Rummeny, Conrad, Erhard and Tolha, 2004), expectation (Koyama, McHaffie, Laurienti and Coghill, 2005), catastrophizing (Seminowicz and Davis, 2006) and emotion (Ochsner, Ludlow and Knierim, 2006) play a major role.

The advance in our understanding of pain mechanisms had lead to improved methods of management by allowing more efficient usage of other therapies like hypnosis. Hypnosis researchers have long sought for physiological indicators of the hypnotic analgesia. Such studies have monitored the effect of hypnosis on autonomous responses such as changes in heart rate, galvanic skin responses (Pascalis and Perrone 1996; Balocchi, Varanini, Menicucci, Santarcangelo, Migliorini, Fontani and Carli, 2005; Santarcangelo, Carli, Migliorini, Fontani, Varanini and Balocchi, 2008) and endothelial function (Jambrik, Carli, Rudish, Varga, Forster and Santarcangelo, 2005). These aspects of hypnotic analgesia have become particularly intriguing due to the evidence that the autonomic activity is monitored in cerebral areas and this information is integrated at higher levels where it contributes to the construction of the experience (Damasio, 1999; Critchley, Wiens, Rotshtein, Ohman and Dolan, 2004; Pollatos, Schandry, Auer and Kaufmann, 2007). As recently suggested by Carli, Huber and Santarcangelo (2008), the peculiar autonomic control observed in highly hypnotizable individuals might account for possible differences in the likelihood of low and high susceptible subjects to suffer with chronic pain as well as for possible differences between the two groups in the cardiovascular damage associated with chronic pain.

There is also evidence that hypnotic analgesia is associated with changes in the RIII component of the nociceptive reflexes (Kiernan, Dane, Philips and Price, 1995), although heat detection and heat-pain thresholds were increased under hypnosis, whereas heat pain tolerance and cold detection thresholds were not statistically changed (Langlade, Jussiau, Lamonerie, Marret and Bonnet, 2002). In addition, hypnotic suggestions alter pain sensation in both high and low susceptible subjects, but the changes are selective and somatotopically organized only in highly susceptible subjects (Benhaiem, Attal, Chauvi, Brasseur and Bouhassira, 2001)

Electroencephalographic (EEG) and evoked potential (EP) studies done since the late 1970s have shown some physiological correlates reflecting hypnotic analgesia (Halliday and Mason 1964; Meszaros, Banyai and Greguss, 1980; Barabasz and Lonsdale 1983; Spiegel, Bierre and Rootenberg, 1989; Arendt-Nielsen, Zachariae and Bjerring, 1990; Meier, Klucken, Soyka and Bromm, 1993; Zachariae and Bjerring 1994; Crawford, Knebel, Kaplan, Vendemia, Xie, Jamison and Pribram, 1998; De Pascalis, Magurano and Bellusci, 1999). In summary, these studies observed reductions in late somatosensory potentials evoked by nociceptive stimuli during hypnosis, linked to perceived pain intensity changes which seem not to be under conscious control. Unfortunately, these EP experiments did not disentangle the influence of suggestion from the hypnotic context. De Pascalis, Magurano, Bellusci and Chen (2001) tested somatosensory event-related potentials to noxious stimuli varying cognitive strategies - deep relaxation dissociative imagery and focuses analgesia. They observed that the effect of pain modulation is limited to high hypnotizable subjects rather than low, and that higher frontal - temporal N2 and smaller posterior parietal P3 may indicate active inhibitory processes during cognitive strategies in hypnotic analgesia. These inhibitory processes may also regulate the autonomic activities on pain perception. Hypnotically induced analgesia was also 
studied by recording intracranial somatosensory event-related potentials (SEPs) to painful cutaneous stimuli during hypnotically suggested analgesia. Kropotov, Crawford and Polyakov (1997) found that the hypnotically responsive patient reduced pain perception during suggested hypnotic analgesia and observed a reduction of the positive SEP component within the range of 140-160 ms post-stimulus in the left anterior cingulate cortex and an enhancement of the negative SEP component occurring after 200-260 ms in the left anterior temporal cortex (Brodman area (BA) 21). Their study was the first to demonstrate the involvement of the anterior cingulate cortex and the anterior temporal cortex in the inhibitory control of pain during hypnotically suggested analgesia.

Surface EEG recordings during hypnotic induced analgesia in volunteers with high versus low hypnotic suggestibility scores have subsequently shown greater theta activity among those subjects with high scores, especially in the anterior temporal region (Crawford 1990). These volunteers also showed greater left hemisphere dominance during the pain condition and a reversal in hemispheric dominance during hypnotic analgesia (Crawford, 1990; De Pascalis and Perrone, 1996). These results were interpreted as reflecting greater cognitive flexibility and abilities to shift from left to right anterior brain functioning. It was proposed that hypnosis may operate via attention filtering with a central role for the frontal limbic system. Attempts to summarize the EEG differences in terms of frequency dominance and coherence (alpha, beta, theta power for hemispheric lateralization), together (Spiegel and Barabasz 1988; Crawford and Gruzelier, 1992) showed such methodological differences that it seems not possible to propose a common physiological substrate (Barabasz, Barabasz, Jensen, Calvin, Trevisan and Warner, 1999). De Pascalis, Marucci and Penna (1989) presented a wide range of studies in support of the modulation of gamma oscillations in the construction of hypnotic changes of consciousness. More recently, Trippe, Weiss and Miltner (2004) reported a breakdown in EEG functional connectivity in the gamma band between somatosensory and frontal cortical regions. They hypothesized that hypnosis may result from inhibitory influences on the secondary somatosensory cortex (S2)/insula regions from the right lateral prefrontal cortex. They argue that hypnosis is characterized by a breakdown on coherent large-scale cortical oscillations organized and controlled by regions in the frontal cortex. Fractal analysis of EEG in hypnosis and its relationship with hypnotizability was studied by Lee, Spiegel, Kim, Lee, Kim, Yang, Choi, Kho and Nam in 2007. They found that the application of this analysis technique can demonstrate the electrophysiological correlations with hypnotic influence on cerebral activity.

Neuroimaging techniques also facilitate efforts for an improved understanding of the brain mechanisms involved in pain experience and hypnosis. Hypnosis induced changes in pain perception and the underlying brain mechanisms were studied by Rainville, Duncan, Price, Carrier and Buschnell (1997). They used the PET scan technique to study brain activity of volunteers exposed to hot water induced pain during hypnotically induced analgesia inducing changes in perceived unpleasantness, but not in the intensity of the noxious stimulation. They found that hypnosis related changes of the affective dimension of pain were associated with changes in activity in anterior and mid-cingulate cortices, but not with activity in primary somatosensory cortex. Faymonville, Laureys, Degueldre, DelFiore, Luxen, Franck, Lamy and Maquet (2000) investigated brain mechanisms underlying the modulation of pain perception without specific suggestion for hypnotic pain reduction. Their hypnotic protocol relied on their clinical experience where patients were invited to have revivication of pleasant autobiographic experiences without any instruction of analgesia (Faymonville, Meurisse and Fissette, 1999). This technique lowers both the affective and the sensory component of the noxious stimuli. Hypnosis 
was shown to decrease both components of pain perception by more than $50 \%$ as compared to resting state conditions and by approximately $40 \%$ as compared to a control distraction task based on mental imagery of autobiographical events. Both studies (Rainville, Duncan, Price, Carrier and Buschnell, 1997 and Faymonville, Laureys, Degueldre, DelFiore, Luxen, Franck, Lamy and Maquet, 2000) showed that the analgesic effect of hypnosis is mediated by the anterior/mid-cingular cortex (Brodmann's area $\left.24^{\prime} \mathrm{a}\right)$. This area is innervated by a multitude of neuromodulatory pathways including opioidergic, noradrenergic and serotoninergic systems (Paus, 2001). The anterior cingulate cortex (ACC) is a functionally heterogeneous region thought to modulate the interaction between cognition, sensory perception and motor control (Vogt, 2005) in relation to changes in attentional, motivational and emotional states (Devinsky, Morrell and Vogt, 1995). In order to further explore the antinociceptive effects of hypnosis, Faymonville, Roediger, Del Fiore, Degueldre, Phillips, Lamy, Luxen, Maquet and Laureys (2003) subsequently assessed the hypnosis-induced changes in functional connectivity involved in noxious processing. The hypnosis-induced reduction of pain perception was shown to be related to an increased functional modulation of the ACC and a network of cortical and subcortical structures known to be involved in different aspects of pain processing encompassing prefrontal, insular and pregenual cortices, pre-supplementary motor cortex, thalami, striatum and brainstem. Functional brain connectivity studies suggest that the anterior cingulated and the prefrontal cortices exert their effects by modulating activity in the midbrain periaqueductal gray, a structure that is of utmost importance in the descending noxious inhibitory system (DNIS) (Faymonville, Vogt, Maquet and Laureys, in press).

\section{Summary and conclusion}

Many factors influence a patient's response to pain, and they are as important as the extent of the physical damage causing it. They include personality, cultural background, previous experience, the significance of the organ involved as well as social and economic factors. Psychologically mediated forms of pain reduction, as shown during hypnotic procedure, not only modulate nociceptive reflexes and pain-related autonomic activity elicited by peripherical stimulation, but also supraspinal pain-control system. Functional imaging studies have identified activation in midcingulate cortex, area 24'a as directly mediating the changes in pain perception specific to hypnotic suggestion. Hypnosis was found to enhance functional modulation between midcingulate area 24'A and a wide network of sensory affective, cognitive and motor-related brain regions. This short review of neurophysiological correlates of hypnotic modulation of pain reinforce the idea, that not only pharmacological but also psychological strategies for relieving pain can modulate the interconnected network of cortical and subcortical regions that participate in the processing of painful stimuli.

\section{Acknowledgments}

This research was funded by the Belgian National Funds for Scientific Research (FNRS), the European Commission, the James McDonnell Foundation, the Mind Science Foundation, the French Speaking Community Concerted Research Action (ARC-06/11-340), the Fondation Médicale Reine Elisabeth and the University of Liège. A.V. was funded by ARC 06/11-340, M.B. is research fellow at the FNRS, S.L. are senior research associate at the FNRS. 


\section{References}

Arendt-Nielsen L, Zachariae R, Bjerring P (1990) Quantitative evaluation of hypnotically suggested hyperaesthesia and analgesia by painful laser stimulation. Pain 42: 243-51.

Balocchi R, Varanini M, Menicucci D, Santarcangelo EL, Migliorini S, Fontani G, Carli G (2005) Heart rate variabilità in subjects with different hypnotic susceptibility receiving nociceptive stimulation and suggestions of analgesia. IEEE Engineering in Medicine and Biology 27: 6996-9.

Bantick SJ, Wise RG, Ploghaux A, Clare S, Smith SM, Tracey I (2002) Imaging how attention modulates pain in humans using functional MRI. Brain 125: 310-19.

Barabasz A, Barabasz M, Jensen S, Calvin S, Trevisan M, Warner D (1999) Cortical event-related potentials show the structure of hypnotic suggestions is crucial. International Journal of Clinical and Experimental Hypnosis 47: 5-22.

Barabasz AF, Lonsdale C (1983) Effects of hypnosis on P300 olfactory evoked potential amplitudes. Journal of Abnormal Psychology 92: 520-3.

Barber TX (1969) Hypnosis: A Scientific Approach. New York: Van Nostrand Reinhold.

Benhaiem JM, Attal N, Chauvin M, Brasseur L, Bouhassira D (2001) Local and remote effects of hypnotic suggestion of analgesia. Pain 89: 167-73

Brooks JC, Nurmikko TJ, Bimson WE, Singh KD, Roberts N (2002) fMRI of thermal pain: effects of stimulus laterality and attention. Neuroimage 15: 293-301.

Carli G, Huber A, Santarcangelo EL (2008) Hypnotizability and chronic pain: an ambiguous connection. Contemporary Hypnosis 25: 65-77.

Carlsson K, Petrovic P, Skare S, Petersson KM, Ingvar M (2000) Tickling expectations: neural processing in anticipation of a sensory stimulus. Journal of Cognitive Neurosciences 12: 691-703.

Coghill RC, Sang CN, Maisog JM, Iadarola MJ (1999) Pain intensity processing within the human brain: a bilateral, distributed mechanism. Journal of Neurophysiology 82: 193443.

Crawford HJ (1990) Cognitive and psychophysiological correlates of hypnotic responsiveness and hypnosis. In: ML Mass and D Brown (eds) Creative Mastery in Hypnosis and Hypnoanalysis: A Festschrift for Erika Fromm. Hillsdale, NJ: Erlbaum, 47-54..

Crawford HJ, Knebel T, Kaplan L, Vendemia JM, Xie M, Jamison S, Pribram KH (1998). Hypnotic analgesia: 1. Somatosensory event-related potential changes to noxious stimuli and 2. Transfer learning to reduce chronic low back pain. International Journal of Clinical and Experimental Hypnosis 46: 92-132.

Crawford JH, Gruzelier J (1992) A midstream view of the neuropsychophysiology of hypnosis: recent research and future directions. In: E Fromm and MR Nash (eds) Contemporary Hypnosis Research. The Guilford Press, New York:, 227-66.

Critchley HD, Wiens S, Rotshtein P, Ohman A, Dolan RJ (2004) Neural systems supporting interoceptive awareness. Nature Neuroscience 7: 189-95.

Damasio A (1999) The Feeling of What Happens: Body and Emotions in the Making of Consciousness. New York: Harvest.

De Pascalis V, Perrone M (1996) EEG Asymmetry and heart rate during experience of hypnotic analgesia in high and low hypnotizables. International Journal of Psychophysiology 21: $163-75$.

De Pascalis V, Magurano MR, Bellusci A (1999) Pain perception, somatosensory event-related potentials and skin conductance responses to painful stimuli in high, mid and low hypnotizable subjects: effects of differential pain reduction strategies. Pain 83: 499-508.

De Pascalis V, Magurano MR, Bellusci A, Chen AC (2001) Somatosensory event-related potential and autonomic activity to varying pain reduction cognitive strategies in hypnosis. Clinical Neurophysiology 112: 1475-85.

De Pascalis V, Marucci FS, Penna PM (1989) 40 Hz EEG asymmetry during recall of emotional events in waking and hypnosis: differences between low and high hypnotizables. International Journal of Psychophysiology 7: 85-96. 
Derbyshire SW, Whalley MG, Stenger VA, Oakley DA (2004) Cerebral activation during hypnotically induced and imagined pain. Neuroimage 23: 392-401.

Derbyshire SWG, Jones AKP, Creed F, Starz T, Meltzer CC, Townsend DW, Peterson AM, Firestone L (2002) Cerebral responses to noxious thermal stimulation in chronic low back pain patients and normal controls. Neuroimage 16: 158-68.

Derbyshire SWG, Vogt BA, Jones AKP (1998) Pain and Stroop interference tasks activate separate processing modules in anterior cingulate cortex. Experimental Brain Research 118: $52-60$.

Devinsky O, Morrell MJ, Vogt BA (1995) Contributions of anterior cingulate cortex to behaviour. Brain 118: 279-306.

Faymonville ME, Laureys S, Degueldre C, DelFiore G, Luxen A, Franck G, Lamy M, Maquet P (2000) Neural mechanisms of antinociceptive effects of hypnosis. Anesthesiology 92: $1257-67$.

Faymonville ME, Meurisse M, Fissette J (1999) Hypnosedation: a valuable alternative to traditional anaesthetic techniques. Acta Chirurgica Belgica 99: 141-6.

Faymonville ME, Mambourg PH, Joris J, Vrijens B, Fissette J, Albert A, Lamy M (1997) Psychological approaches during conscious sedation. Hypnosis versus stress reducing strategies: a prostective randomized study. Pain 73: 361-7.

Faymonville ME, Roediger L, Del Fiore G, Degueldre C, Phillips C, Lamy M, Luxen A, Maquet P, Laureys S (2003) Increased cerebral functional connectivity underlying the antinociceptive effects of hypnosis. In: Cognitive Brain Research 17: 255-262.

Faymonville ME, Vogt B, Maquet P, Laureys S (in press) Hypnosis and cingulate-mediated mechanisms of analgesia. In: B. Vogt (ed.) Cingulate Neurobiology and Disease. Oxford: Oxford University Press.

Gruzelier JH (2000) Redefining hypnosis: theory, methods and integration. Contemporary Hypnosis 17: $51-70$.

Halliday AM, Mason AA (1964) Cortical evoked potentials during hypnotic anaesthesia. Electroencephalography and Clinical Neurophysiology 16: 312-14.

Hilgard ER (1965) The Experience of Hypnosis. San Diego, New York, London, A Harvest/HBJ Book.

Hoffman HG, Richards TL, Coda B, Bills AR, Blough D, Richards AL, Sharar SR (2004) Modulation of thermal pain-related brain activity with virtual reality: evidence from fMRI. Neuroreport 15: 1245-8.

Holroyd (1996) Hypnosis treatment of clinical pain: understanding why hypnosis is useful. International Journal of Clinical and Experimental Hypnosis 44: 33-51.

Hsieh JC, Stone-Elander S, Ingvar M (1999) Anticipatory coping of pain expressed in the human anterior cingulate cortex: a positron emission tomography study. Neuroscience Letters 262: $61-4$.

Jambrik Z, Carli G, Rudish T, Varga A, Forster T, Santarcangelo EL (2005) Modulation of paininduced endothelial dysfunction by hypnotisability. Pain 116: 181-6.

Jamieson GA (2007) Previews and prospects for the cognitive neuroscience of hypnosis and conscious states. In: JA Jamieson (ed.) Hypnosis and Conscious States: The cognitive neuroscience perspective. New York: Oxford University Press, 1-11.

Kallio S, Revonsuo A (2003) Hypnotic phenomena and altered states of consciousness: a multi-level framework of description and explanation. Contemporary Hypnosis 20: 11164

Kiernan BD, Dane JR, Philips LH, Price DD (1995) Hypnotic analgesia reduces the R III reflex nociceptive reflex: further evidence concerning the multi-factorial nature of hypnotic analgesia. Pain 6: 39-47.

Kirsch I (1991) The social learning theory of hypnosis. In: SJ Lynn, JW Rhue (eds) Theories of Hypnosis: Current Models and Perspectives. New York: Guilford Press, 439-66.

Koyama T, McHaffie J, Laurienti P, Coghill R (2005) The subjective experience of pain: where expectations become reality. PNAS 102: 12950-5. 
Kropotov JD, Crawford HJ, Polyakov YI (1997) Somatosensory event-related potential changes to painful stimuli during hypnotic analgesia: anterior cingulate cortex and anterior temporal cortex intracranial recordings. International Journal of Psychophysiology 27: 1-8.

Kupers R, Faymonville ME, Laureys S (2005) The cognitive modulation of pain: hypnosis- and placebo-induced analgesia. Progress in Brain Research 150: 251-69.

Lang EV, Benotsch EG, Fick LJ, Lutgendorf S, Berbaum ML, Berbaum KS, Logan H, Spiegel D (2000) Adjunctive non-pharmacological analgesia for invasive medical procedures: a randomized trial. The Lancet 355: 1486-90.

Langlade A, Jussiau C, Lamonerie L, Marret E, Bonnet F (2002) Hypnosis increases heat detection and heat pain thresholds in healthy volunteers. Regional Anesthesia and Pain Medicine 27: $43-6$.

Laureys S (2005) The neural correlate of (un)awareness: lessons from the vegetative state. TRENDS in Cognitive Sciences 9: 556-9.

Laureys S, Boly M, Tononi G (2008) Functional neuroimaging. In: S Laureys, G Tononi (eds) The Neurology of Consciousness. New York: Academic Press, 31-42.

Lee JS, Spiegel D, Kim SB, Lee JH, Kim SI, Yang BH, Choi JH, Kho YC,Nam JH (2007) Fractal analysis of EEG in hypnosis and its relationship with hypnotizability. International Journal of Clinical and Experimental Hypnosis 55: 14-31.

Meier W, Klucken M, Soyka D, Bromm B (1993) Hypnotic hypo- and hyperalgesia: divergent effects on pain ratings and pain-related cerebral potentials. Pain 53: 175-81.

Melzack R, Casey KL (1968) Sensory motivational and central control determinants of pain: a new conceptual model. In: D Kenshalo (ed.) The Skin Senses. Springfield: Thomas, 423-43.

Melzack R, Wall PD (1965) Pain mechanisms: a new theory. Science 150: 971-8.

Meszaros I, Banyai EI, Greguss AC (1980) Evoked potential, reflecting hypnotically altered state of consciousness. In: G Adam, I Meszaros, EI Banyai (eds) Advances in Physiological Sciences, vol 17. Brain Behavior. Oxford: Pergamon, 467-75.

Montgomery GH, David D, Winkel G, Silverstein JH, Bobbjerg DH (2002) The effectiveness of adjunctive hypnosis with surgical patients: a meta-analysis. Anesthesia and Analgesia 94: $1639-45$.

Montgomery GH, DuHamel KN, Redd WH (2000) A meta-analysis of hypnotically induced analgesia: how effective is hypnosis? International Journal of Clinical and Experimental Hypnosis 48(2): 138-53.

Ochsner K, Ludlow D, Knierim K (2006) Neural correlates of individual differences in painrelated fear and anxiety. Pain 120: 69-77.

Pascalis V, Perrone M (1996) EEG asymmetry and heart rate during experience of hypnotic analgesia in high and low hypnotizables. International Journal of Psychophysiology 21(2-3): $163-75$.

Patterson DR, Jensen MP (2003) Hypnosis and clinical pain. Psychological Bulletin 129: 495-521.

Paus T (2001) Primate anterior cingulate cortex: where motor control, drive and cognition interface. Nature Reviews Neuroscience 2: 417-24.

Petrovic P, Kalso E, Peterson KM, Ingvar M (2002) Placebo and opioid analgesia - imaging a shared neuronal network. Science 295: 1737-40.

Peyron R, Laurent B, Garcia Larrea L (2000) Functional imaging of brain responses to pain. A review and meta-analysis. Clinical Neurophysiology 30: 263-88.

Ploghaus A, Becerra L, Borras C, Borsook D (2003) Neural circuitry underlying pain modulation: expectation, hypnosis, placebo. TRENDS in Cognitive Sciences 7: 197-200.

Ploghaus A, Tracey I, Gati JS, Clare S, Menon RS, Matthews PM, Rawlins JN (1999) Dissociating pain from its anticipation in the human brain. Science 284: 1979-81.

Pollatos O, Schandry R, Auer DP, Kaufmann C (2007) Brain structures mediating cardiovascular arousal and interoceptive awareness. Brain Research 1141: 178-87.

Rainville P, Duncan GH, Price DD, Carrier B, Buschnell MC (1997) Pain affect encoded in human anterior cingulate but not somatosensory cortex. Science 277: 968-71. 
Santarcangelo EL, Carli G, Migliorini S, Fontani G, Varanini M, Balocchi R (2008) Heart rate control during pain and suggestions of analgesia without deliberate induction of hypnosis. International Journal of Clinical and Experimental Hypnosis 56: 255-69.

Sawamoto N, Honda M, Okada T, Hanakawa T, Kanda M, Fukuyama H, Konishi J, Shibasaki H (2000) Expectation of pain enhances responses to nonpainful somatosensory stimulation in the anterior cingulate cortex and parietal operculum/posterior insula: an event-related functional magnetic resonance imaging study. Journal of Neuroscience 20: 7438-45.

Seminowicz D, Davis K (2006) Cortical responses to pain in healthy individuals depends on pain catastrophizing. Pain 120: 297-306.

Spanos NP (1986) Hypnotic behavior: a social psychological interpretation of amnesia, analgesia and 'trance logic'. Behavioral and Brain Sciences 9: 449-67.

Spiegel D, Barabasz AF (1988) Effects of hypnotic instructions on P300 event-related-potential amplitudes: research and clinical implications. American Journal of Clinical Hypnosis 31: $11-17$.

Spiegel D, Bierre P, Rootenberg J (1989) Hypnotic alteration of somatosensory perception. American Journal of Psychiatry 146: 749-54.

Stewart JH (2005) Hypnosis in Contemporary Medicine. Mayo Clinic Proceedings 80: 511-24.

Tölle TR, Kaufmann T, Siessmeier T, Lautenbacher S, Berthele A, Munz F, Zieglgänsberger W, Willoch F, Schwaiger M, Conrad B, Bartenstein P (1999) Region-specific encoding of sensory and affective components of pain in the human brain: a positron emission tomography correlation analysis. Annals of Neurology 45: 40-7.

Trippe RH, Weiss T, Miltner WHR (2004) Hypnotisch-induzierte Analgesie - Mechanismen. Anästhesiologie \& Intensivmedizin 45: 642-7.

Valet M, Sprenger T, Boecker H, Willoch F, Rummeny E, Conrad B, Erhard P, Tolha TR (2004) Distraction modulates connectivity of the cingulo-frontal cortex and the midbrain during pain - an fMRI analysis. Pain 109: 399-408.

Vogt BA (2005) Pain and emotion interactions in subregions of the cingulate gyrus. Nature Reviews Neuroscience 6: 533-44.

Zachariae R, Bjerring P (1994) Laser-induced pain-related brain potentials and sensory pain ratings in high and low hypnotizable subjects during hypnotic suggestions of relaxation, dissociated imagery, focused analgesia, and placebo. International Journal of Clinical and Experimental Hypnosis 42: 56-80.

Address for correspondence:

Marie-Elisabeth Faymonville

Pain Clinic, University Hospital of Liège

Sart-Tilman

4000 Liège

Belgium

Phone: 003243668033

e-mail: mfaymonville@chu.ulg.ac.be 